\title{
A figura literária do soter em Os Sertões
}

Délia Cambeiro I UERJ

\begin{abstract}
Resumo: Este artigo visa a analisar de que modo se construiu a figura literária de Antônio Vicente Mendes Maciel - o Conselheiro. No diálogo do texto com o contexto, analisam-se passagens de Os sertões, de Euclides da Cunha, obra revista pela crítica de Ataliba Nogueira e de Roberto Ventura. Utilizou-se uma leitura baseada na categoria sagrado, além do apoio teórico de Pierre Brunel, para concluir-se que na metamorfose do Conselheiro permanece a figura do soter.

Palavras-chave: sagrado, messianismo, mito.
\end{abstract}

\section{Questionamentos iniciais}

Refletir sobre Canudos e seu carismático líder, 105 anos após a passagem do Anjo da Morte pelo arraial, não é só pensar a importância da obra nem do fenômeno que o eternizou. Retomar o assunto é importante exercício de questionamento da condição e dos valores essenciais da humanidade principalmente em tempos de obstinado investimento niilista que reforça o sentido de fragmentação da vida. 
A análise da figura literária do Conselheiro eternizada por Euclides da Cunha ${ }^{1}$, em sua obra Os sertões, desvela ao pesquisador de mito e de sagrado um homem radicalmente envolvido na força dinamizadora do sacer ${ }^{2}$, ou seja, do sagrado primacial que guarda a pureza do fundamento de tudo. Segundo os critérios de tal investigação, de fato, o líder sertanejo semeou como critério de Verdade absoluta da vida a transcendência, porém, não se pode negar, também tentou dignificar seus fiéis, organizando-os no mundo material. Naquele momento e naquela desfavorecida geografia, a idéia de absoluto e de transcendência, já questionada por novos fluxos do pensamento filosófico, ainda exercia seu vigor e era capaz de unir exilados, sublimando na esfera do sagrado os problemas crônicos da esfera social.

Hoje, além das citadas categorias, também outras concernentes à religiosidade quedaram-se esvaziadas sob o impacto da pulverização do significado de Deus já deflagrada por Nietzsche. Talvez em decorrência dessa dúvida o mundo apresente-se sombreado por radical singularização do vulgar, por visível perda dos valores supremos e eternos, apesar do recrudescimento das investidas de seitas religiosas nas últimas décadas. O homem atravessa agora radical fragmentação da vida ecleticamente convertida em simulacros e em pastiches. Tais experiências, como afirma M. Eliade, ${ }^{3}$ conduzem ao descrédito e ao vazio o ser humano transformado em "massa disforme e já desprovida de um omphalos orientador" - o que não acontecia no utópico espaço de Canudos.

1. Este trabalho é síntese da Tese de Doutorado em Literatura Comparada "A figura do herege: Eon de l'Etoile e Antônio Conselheiro", defendida na Faculdade de Letras da UFRJ em 1999.

2. "Sacer", ou seja, "salvador" - do grego soterion - está ligado a outras categorias, tais como, mito, sagrado, utopia, messianismo e milenarismo. Sugere a chegada do Milênio e a proclamação do Reino Messiânico, porém, mais do que isso, aponta para a esperada sociedade preconizada por Cristo em que todos seriam iguais perante o Pai. Antes da volta gloriosa de Jesus - a parusia - e sua interferência na História, tais promessas de salvação espiritual e de igualdade social podem ser apresentadas por uma outra figura capaz de unir os homens no campo espiritual e também esclarecê-los no âmbito material. O "soter", portanto, não se refere apenas a Jesus, mas a um ser reconhecido por sua importância no grupo. Ver: ENCICLOPÉDIA. Lisboa: Imprensa Nacional/ Casa da Moeda/Einaudi, 1987. v. 12; OTTO, Rudolf. O sagrado. Lisboa: Edições 70, 1992; SÉGUY, Jean. Messianismes et millénarisme. Ou de l'attente comme catégorie de l'agir social, In: CHAZEL, F. Action colletive et moviments sociaux. Paris: PUF, 1993.

3. ELIADE, [s.d.], passim. 
Investigar e atualizar, sob o prisma de mitoe de sagrado, o movimento de Canudos e seu mentor constitui, portanto, intrincado caminho aberto em meio a pedras da banalidade de um quotidiano sem compromisso de perenidade e esquecido da questão sobre a verdade ou a salvação da alma, tão discutidos, por exemplo, na Idade Média. Não faria sentido, portanto, um olhar de investigação mítico-sagrada presa do tempo e da geografia. Ao contrário, a releitura da representação literária do Conselheiro, visando à constante reflexão sobre o movimento por ele liderado, reatualiza temas essenciais da humanidade - entre eles mito e sagrado - latentes no ambiente descrito por Euclides da Cunha.

A validade de tal pesquisa para o século XXI é assegurada por alguns estudiosos - teólogos, sociólogos da religião, mitólogos, etc. - que, em meio ao caos da "derrota de Deus", pressentem, e por isso investigam, a tentativa de o homem reconectar-se com o sagrado. Segundo essas obras, o tipo de conexão com a transcendência ocorrida em Canudos evidencia um "fenômeno que visa utilizar a religião em função de exigências de natureza social. ${ }^{5}$ Mas o objetivo de tais indagações concentra-se na dimensão do sagrado "fora da lógica de compensação e de segurança que orienta a busca de formas de identidade e de segurança social". ${ }^{6}$ Pretendem assinalar, em especial, que, só assim, a busca da transcendência "não é mais ditada pelo desejo de preencher uma carência, mas é sobretudo uma disposição para a escuta".

É evidente que tais indagações sobre mito e sagrado tencionam rigorosa verticalização conceitual apta a uma leitura universalizante e atemporal da condição humana. Seria impossível, porém, (re)pensar o fenômeno Canudos apenas enraizado na "escuta" da voz do sagrado, sem associá-lo à compensação social, sem ligá-lo à evidente "carência" material.

Este trabalho, orientado por tal perspectiva, visa a demonstrar de que forma está delineada, na obra Os sertões, a figura do Conselheiro e sublinhar seu papel de condutor espiritual e social, ou seja, o soter capaz de guiar um grupo em crise, prometendo a todos tanto a felicidade de uma sociedade sem classes quanto a salvação da alma no pós-morte.

4. QUINZIO, 1978, passim.

5. CRESPI, 1999. p. 9-24.

6. CRESPI, 1999. p. 9-24.

7. CRESPI, 1999, passim. 


\section{A configuração do soter}

Não fora a escolha existencial de Antônio Vicente Mendes Maciel, o Conselheiro, pelo sagrado, como forma de apaziguar-se com a vida e não fora também sua palavra persuasiva, objetivando conduzir o outro à salvação o que, paradoxalmente, provocou uma das maiores carnificinas de que se tem conhecimento no Brasil - sua vida seria mais uma seqüência de fatos apagados e sofridos no isolamento e no anonimato do sertão.

Foi provavelmente a partir de experiências pessoais negativas e após um ocultamento como andarilho pelo sertão que teria sonhado para si e para seus seguidores um projeto de vida comunitária, visando à criação e à plantação coletivas, atraindo o fluxo de fiéis e peregrinos. Já estabelecido em Canudos, é rejeitado e visto como um herege pregador de idéias heterodoxas, sendo perseguido junto com os conselheiristas. Assentados em sua cidade no difícil momento social de passagem do Império para a República e apesar dos desmandos das classes dominantes, no espírito dos humildes circulava a certeza de que tinham alguém para defendê-los do/no sofrimento.

$\mathrm{Na}$ visão dos sertanejos o Conselheiro encarnava seguramente aquele que restituiria um código de Verdade que construiria uma utópica geografia da fraternidade e da fartura. Lembrando um Pays de Cocagne ${ }^{8}$ da fartura, sem fome - o mundo às avessas de que a Idade Média tanto se alimentou - uma "terra de promissão, onde corre um rio de leite e são de cuscuz de milho as barrancas", o pobre arraial realizava o paraíso perfeito onde não se precisaria trabalhar para um senhor escravizador. Mantidas diferenças e identidades geográficas e culturais, convém lembrar quanto ao tema da utopia realizada que Euclides da Cunha se referiu a Canudos como um "falanstério", pois, de fato, a comunidade assemelhava-se pelo sentido da paixão ${ }^{10}$ que os uniu à que Charles Fourier idealizava concretizar. Em Canudos, os homens se reuniam segundo o princípio da semelhança de idéias e de objetivos. A terra de promissão, entretanto, foi derrubada à bala, ao entardecer de 5 de outubro de 1897.

No "retrato" literário do fundador de Canudos ficou estampado um "paranóico" fruto de carências pessoais e sociais, um predestinado que

8. FRANCO JUNIOR, H., 1992. p. 23-49.

9. CUNHA, E., 1993. p. 149.

10. KONDER, L., 1998, passim. 
anunciava com o verbo incandescido para um futuro bem próximo o Juízo Final que, além da parusia, traria uma era de justiça e de felicidade para fiéis e arrependidos. A análise da representação, no entanto, revigora o mito sempre presente no inconsciente coletivo do condutor de almas e do organizador do povo: ou seja, o soter, o salvador capaz de estabelecer total diálogo entre comandados e comandante.

Para o mitólogo francês Pierre Brunel, ${ }^{11}$ tais manifestações representam metamorfoses do mito primitivo, encarnariam expressões inconscientes do renascimento de figuras arquetípicas. Segundo tal leitura crítica, vê-se ressurgir, portanto, por intermédio do Conselheiro, a personificação do soter arquetípico.

O líder sertanejo, sempre presente em tudo o que se relacionasse com seu "reino", conseguiu uni-los e reuni-los mística e socialmente na oração com a disciplina da fé inviolável. Descrito na forma de um estóico "gnóstico bronco" que norteara a vida "sem duvidar da Providência" e de um ambíguo "Hércules-Quasímodo", em verdade o Conselheiro lutou contra fatores de ordem natural, pessoal e coletiva. Qualquer que tenha sido a crítica a ele endereçada, deve-se enfatizar que sua práxis assinalou uma evasão para problemas insolúveis de ordem coletiva.

Configura-se em Os sertões um paranóico desenhista de imagens apocalípticas para atemorizar e impressionar seus ouvintes. As adjetivações empregadas evidenciam que o Conselheiro provocou em Euclides da Cunha estarrecida curiosidade de ordem científica, sempre marcada pela linguagem das doenças psíquicas. Seu "diagnóstico", a cada momento, tenta convencer o leitor de estar frente a um obsessivo "doente grave". No entender de Roberto Ventura, dentre outras condições, a observação do escritor foi prejudicada por sua "formação científica, de base positivista e evolucionista, com os preconceitos raciais próprios da época, que traziam a crença na inferioridade dos não-brancos". ${ }^{12}$

Uma reflexão sobre tal fenômeno orientada pela hipótese da metamorfose do mito proposta por Pierre Brunel transforma sensivelmente o julgamento da palavra e da ação do orientador de almas, constantemente carregadas de delírios apocalípticos, conforme interpretação euclidiana. Os fiéis e seu líder repetiam, assim, atitudes atemporais, perdidas em brumoso

\section{BRUNEL, P., 1974, passim.}

12. veNTURA, R., apud ABDALA JR. \& ALEXANDRE, I. 1997, p. 89-99. 
histórico humano que só legaram seu testemunho por meio da memória mítica. Com os ensinamentos daquele Hércules-Quasímodo, sentiam ser possível materializar-se a sonhada utopia de esperança, de felicidade e de paz futuras, veiculadas na mensagem que o atraíram. Pela efetiva mobilização interior e exterior produzida pela palavra, o humilde "missionário das alturas" representaria para os marginalizados sertanejos "o delegado dos céus". Entretanto, Euclides da Cunha enfatiza, com insistência, o ângulo Quasímodo, o aspecto grotesco do anunciador dos novos tempos a que Antônio Conselheiro se destinara, não eliminando a descrição dos seguidores. O escritor refere-se a obscuras zonas psíquicas de onde saem ou "heróis ou fascínoras, aleijões tacanhos, gênios e degenerados". Coloca, portanto, todos os implicados na seara do "desnorteado apóstolo" nos limites da loucura, do sonho alienador, da paranóia, da insânia.

\section{Escritos da guerra e da fé}

Foi durante campanha do exército contra o arraial que Euclides da Cunha, anotando aquela guerra civil com minúcias de repórter, transforma seus relatos histórico-fotográficos em uma interpretação pessoal do movimento, apresentando-o como exemplo de tendências conflituosas da realidade brasileira. Seria somente após breve permanência na região para acompanhar os acontecimentos, descrevê-los em seu diário e repensá-los que ele mostraria uma outra perspectiva do que se passava: ainda que não tivesse presenciado a tomada e destruição de Canudos. Como assinala Roberto Ventura, nos primeiros escritos sobre a campanha militar, não ficaram registros de sua revolta contra o extermínio. Mas em Os sertões, apesar da interpretação negativa de Canudos e de seus habitantes por parte de seu observador, encontra-se clara atitude denunciadora, pautada até certo ponto em revolta contra a realidade social, classificada de "crime".

Este trabalho quer enfatizar que Antônio Conselheiro, mostrando uma verdade possível em meio a todo aquele desequilíbrio, encarnava uma presença providencial, preenchia o vazio socioeconômico com um forro religioso, interpretado por Euclides da Cunha em leitura muitas vezes fatalista e radical. Percebe-se, ainda, na "economia espiritual" do sertão, que o chefe religioso administrava com mestria o sagrado e o .profano, gerenciaria os valores de uma comunidade vista cientificamente pelo autor como portadora de um comportamento neurótico, plena de marcas profundas de raízes psicológicas, 
repetidas vezes relatadas como insânia mística e paranóia messiânica. Evidenciase que em sua selvagem psicanálise positivista Euclides da Cunha parte de aspectos predominantes da ação catequizadora do Conselheiro, para afirmar ter ele sido "um infeliz, [que] destinado à solicitude dos médicos, veio, impelido por uma potência superior, bater de encontro a uma civilização, indo para a História como poderia ter ido para o hospício".

As personagens daquele humaníssimo drama sociorreligioso serão descritas pelo olhar fascinado do repórter testemunho da História, que não se preocupou apenas em apreender o fenômeno Canudos, mas julgou com descrição minuciosa, "positivista, evolucionista", o objeto investigado. Por isso, guiado por seu modelo pessoal da Verdade, exacerba com exercícios retóricos os seres ali reunidos e as relações entre eles.

$\mathrm{O}$ autor, como se percebe, sugere a religião como forma de alienação, de ópio anestesiador e regressivo da inteligência, causadora, talvez, do "temperamento delirante" e "da insânia" do líder, já mergulhado no estado emotivo de "um cérebro abalado" ao ampliar suas aspirações religiosas, arrastando atrás de si "erros de dous mil anos". O perfil do Conselheiro, nitidamente marcado pela diferença, impunha-se fortemente pelo despojamento de qualquer bem, e isso "era natural (...) já que ele surgia - esquálido e macerado - das chapadas povoadas de duendes".

Ao ser analisado hoje o movimento, a população de fervorosos comungava de uma referência cujo sentido congregador era o de pertencerem a uma comunidade de destino religiosa e material, por isso, quem nela entrasse, entregava boa parte dos bens pessoais, a fim de manter a sobrevivência coletiva. Tal desprendimento estaria de acordo com as prédicas compensatórias do chefe sobre o fim do mundo e a salvação dos escolhidos. Para ele os que pouco ou nada tinham nesta vida receberiam, em troca, do mundo transcendental, já no paraíso, seu quinhão de bem-estar espiritual. Vai-se formando, assim, o povoado da salvação que, para Euclides da Cunha, se apresentou como a urbs monstruosa de barro, "a civitas sinistra do erro". Contudo, na perspectiva de urbs ideal e da cidade de Deus, o vilarejo congraçaria os homens, sem que precisassem se identificar, guardando, em suas rústicas e pobres casas sem camas ou mesas, nada mais do que redes, banquinhos e um oratório com santos toscos, como diz o autor: os fiéis - peregrinos na miséria e na falta - seguiram seus passos espontaneamente, felizes por estarem unidos. Aproximando-se, arquetipicamente, a simbólico Sumo Sacerdote, Antônio Conselheiro imantava a todos 
aqueles que dele se aproximassem, reativando na geografia do sertão a instância do sacer, o sagrado primacial intocável.

É interessante assinalar o trecho em que Euclides da Cunha, baseando-se em relatos, refere-se aos sermões dirigidos aos fiéis. Dimensionando o fato pela imaginação, pois não o presenciou, ressalta o fato de os ouvintes do missionário, hipnotizados por aquela "insânia formidável (...), ouvirem mas não encararem o líder, que sempre mantinha o olhar no chão. Imagine-se, sublinha o autor, "um bufão arrebatado numa visão do Apocalipse”. Além desse grotesco traçado, a figura literária de Antônio Conselheiro avulta, pouco a pouco, impressionando quem o analisa.

Mesmo que em vários momentos os sertões abriguem uma linguagem preconcebida e comentários desavisados sobre a guerra, a obra, no entender de W. Nogueira, "alçou-a à tragédia paradigmática, mediante o louvor à coragem do vencido". ${ }^{13}$ Apesar de revoltar-se, denunciando a guerra como um crime, o autor, porém, não chega - talvez por divergências éticas, socioculturais e mesmo filosóficas -, ao cerne do fenômeno Canudos.

Assinala R. Ventura que a eliminação do arraial deu-se, em razões profundas, não por ser um reduto anti-republicano ou de fanáticos inconseqüentes, mas por questões de conflitos entre facções partidárias da Bahia. Questiona ainda a

atuação da Igreja contra a atuação pouco ortodoxa dos beatos e pregadores e as pressões dos proprietários de terras contra a comunidade, cuja expansão trazia escassez de mão-de-obra e rompia o equilíbrio político da região. ${ }^{14}$

Em seus escritos sobre a guerra, Euclides da Cunha moldou a figura do Conselheiro com traços trágicos que formavam irreparável desvio e isolamento históricos em face do caráter libertador da República, como afirma em sua correspondência. Mas o que se deve sublinhar é que o arraial, sem dúvida, impulsionado pela figura de seu fundador, tornou-se a Utopia possível de que fala E. Bloch, em sua obra Le principe espérance.

Pintado nas linhas da obra euclidiana ficaram os traços de HérculesQuasímodo, mas nos sermões escritos pelo Conselheiro - postos à luz por

13. NOGUEIRA, W., 1972. p. 24.

14. VENTURA, R. apud ABDALA JUNIOR, J. \& ALEXANDRE, I. 1997, p. 89-99. 
Ataliba Nogueira, ${ }^{15}$ revisor de Os sertões e crítico de Euclides - revela-se para o mitólogo um líder religioso e carismático. Tal retrato opõe-se ao de fanático, de profeta sebastianista e milenarista sugerido nos discutidos poemas chamados de ABCs. Estes ABCs eram quadras reproduzidas na famosa obra do engenheiroescritor, interpretadas como escritos do Conselheiro, mas que serviriam à memorização dos feitos do líder. Não caberia e também fugiria aos objetivos deste trabalho analisarem-se os textos de autoria do Conselheiro aqui mencionados, visando à orientação de leitura a revisão histórica.

Deve-se afirmar que a importância da obra escrita do líder sertanejo avulta com devida importância por si mesma, concedendo elementos de questionamento de sua importância. Juntam-se estes às indagações do "profeta" de Canudos, a fim de melhor delinear a sua figura e desenhar Canudos nas linhas de uma geografia letrada. Euclides da Cunha, porém, não chegou a ter acesso aos sermões de Antônio Conselheiro. Após revelações de tal monta, o Conselheiro aparece como um sertanejo dotado de capacidade de expressão escrita para seus pensamentos religiosos, portanto a figura e a ação do líder devem ser repensadas.

Tal fato minimiza a versão euclidiana de sertanejo bronco, sugerida para a imagem já tão cristalizada do Conselheiro. O autor, não se pode negar, mostrou a voz do outro, porém não compreendeu o fenômeno da forma como objetiva este trabalho, que pretende refletir categorias essenciais da humanidade.

\section{Conclusão parcial}

Não se pode negar hoje que o Conselheiro, impregnado da instância do sagrado, manifestou em Canudos a metamorfose do mito do chefe políticoreligioso. Suas expressões de ânsia sagrada, tão esvaziada no anterior e neste século, não foram captadas por Euclides da Cunha que, no final do XIX, concebeu sua representação em forma de agressivo ataque às normas da ética e do equilíbrio psíquico. O imperioso desejo do missionário em participar do mundo do sagrado foi retratado negativamente pelo escritor. Em Os sertões, de fato, a figura literária do Conselheiro, delineada com traços da deformação comportamental, avulta em dramática e irreversível situação de um grave doente mental que, segundo

15. NOGUEIRA, A. 1974, passim. 
o autor, para acentuar mais ainda sua fama negativa, alimentou a paranóia de uma coletividade inteira, ao querer salvá-la do mal e da fome.

Mesmo que na obra euclidiana a figura do líder tenha sido gravada de forma negativa, a tese defendida por P. Brunel sobre a metamorfose do mito propõe nova forma de investigação para o fenômeno, evidenciando que naquele humilde sertanejo continua perenizado através dos tempos o imemorial arquétipo do soter.

Em verdade, na obra permanece reavivado o símbolo do salvador que, devido a pressões sociais e temporais, emergiu vitorioso no deserto do sertão baiano. Finalmente renasce com ele a força de sonhar utopias e de realizá-las, a fim de o homem tentar inaugurar na Terra a almejada felicidade do Paraíso perdido.

Resumé: Cet article se propose d'analyser de quelle façon s'est construite la figure littéraire de Antônio Vicente Mendes Maciel - dit o Conselheiro. Effectuant un dialogue du texte avec son contexte, on s'est servi de passages de Os sertões, d'Euclides da Cunha, oeuvre revue par la critique d'Ataliba Nogueira e de Roberto Ventura. Tout en se fondant sur la téorie de la métamor-phose du mythe, de Pierre Brunel, et sur la catégorie sacré, l'on en conclut qu'au cours de sa métamorphose Conselheiro conserve la figure du soter.

Mots clés: sacré, mythe, critique.

$$
\text { Referências Bibliográficas }
$$

ABDAlA JUNIOR, B.; ALEXANDRE, I. (org.). Canudos: palavra de Deus, sonho da terra. São Paulo: SENAC/Boitempo, 1997.

BRUNEL, P. Le mythe de la métamorphose. Paris: Armand Collin, 1974.

CAMBEIRO, D. A figura do herege: Eon de l'Etoile e Antônio Conselheiro. 1999. Tese (Doutorado em Letras) - Faculdade de Letras, UFRJ, Rio de Janeiro. Mimeografado.

CRESPI, F. A experiência religiosa na pós-modernidade. São Paulo: EDUSC, 1999.

CUNHA, E. Os sertões. São Paulo: Cultrix, 1993.

ELIADE, M. O sagrado e o profano. A essência das religiões. Lisboa: Livros do Brasil, [s.d.]. FRANCO JUNIOR, H. As utopias medievais. São Paulo: Brasiliense, 1992.

KONDER, L. Fourier, o socialismo do prazer. Rio de Janeiro: Civilização Brasileira, 1998. NOGUEIRA, A. Antônio Conselheiro e Canudos (Revisão histórica. Separata da Revista do Instituto Histórico e Geográfico Brasileiro. v. 301, out./dez. 1973). Rio de Janeiro. 1974.

NOGUEIRA, W. O império de Monte Belo: vida e morte de Canudos. São Paulo: Boitempo, 2001 . 